\title{
Application of Fuzzy PI Controller For Wind Power Grid-connected Inverter
}

\author{
${ }^{1}$ Yongqi Tang and Xuan $\operatorname{Lin}^{2}$ \\ ${ }^{1,2}$ College of Electrical and Information Engineering, Hunan Institute of \\ Engineering, Hunan, China \\ ${ }^{1}$ Collaborative Innovation Center of Wind Power Equipment and Energy \\ Conversion, Hunan, China \\ ${ }^{1}$ Hunan Provincial Key Laboratory of Wind Generator and Its Control, \\ Hunan, China \\ 416986074@qq.com
}

\begin{abstract}
Grid-connected inverter plays a significant role in wind power generation system for energy transmission and power factor regulation. The traditional control strategy based on PI-type current controller and grid voltage vector-oriented control is analyzed firstly. Then, the fuzzy PI controller of voltage loop is designed. According to the errors of input value and its ratio, it can adjust PI parameters in real-time on the basis of fuzzy rule. The experiment results indicate that the proposed method has a good sinusoidal current, a fast dynamic response and a perfect system performance.
\end{abstract}

Keywords: Grid-connected Inverter, Fuzzy PI Controller, Grid Voltage Vector-oriented, Power Factor

\section{Introduction}

In the past decades, with the growing crisis of petroleum energy, the restriction of releasing carbon dioxide and the consciousness of protect the natural environment, people are eager to develop a new source to solve these troublesome such as solar energy, wind power, tidal power, terrestrial heat, and nuclear energy[1]. In the long term, as one kind of clear and renewable energy, wind power may become the major alternative energy in the world due to a great number of advantages it possessed[2]. Wind power has enormous economic and social benefits because of its cleanliness and free pollution, short construction period, flexible investment and fewer occupation of land.

Nowadays, there are huge gaps between China and developed countries in wind power's theory and application research, for wind power has disadvantages with thermal power and hydroelectric power in cost, power quality, equipment manufacture and control technology [3]. Research of wind power generation in China is very weak and many advanced wind power technologies are not solved such as LVRT(low voltage ride through), pitch control, variable speed constant frequency, current harmonics, running in unity power factor, and grid-connected efficiency,etc[4]. Therefore, almost all advanced large-scale wind turbine and its matching products are imported from overseas. All in all, in depth research of wind power grid-connected inverter technology has very important meaning for persistent wind power development and home production.

The wind is always influenced by altitude, time, weather and seasons[5], and it is a uncertain and irregular matter. So when we establish the wind power generation system, in fact, people always regard it as a time-varying, nonlinear and sophisticated system[6]. The system designing, the efficiency and the stability of the system are hard to control because the mathematical model of the system is difficult to be described. And, the 
traditional control method has poor effect such as Fixed Pitch Control, PID Control, Pulse Width Modulation Control, etc. Recent years, some intelligent control methods are introduced in the application of wind power generation, including Fuzzy Logic Control, Artificial Intelligence, Genetic Algorithm, Expert System and etc[7].

Among all of the aforementioned intelligent approaches, fuzzy logic control has been extensively studied in the literature [8]. As a kind of typical intelligent control method, fuzzy logical control is widely used in many natural and social science filed, the biggest characteristic is to apply the expert's experience and knowledge expressed as language rule to controlling, it doesn't be depended on the accurate mathematical model of the controlled system, which can overcome the nonlinear and has stronger robustness for the parameter of being adjusted object [9]. Thus, the fuzzy control is very suitable for wind power control system. The development of fuzzy control mainly experienced several stages from being proposed to the present situation. They are: stage I, the application of the basic fuzzy controller; stage II, the application of self-organizing fuzzy controller; stage III, intelligent fuzzy controller. The basic fuzzy controller and the self-organizing fuzzy controller belong to the pure fuzzy controller that are not combined with other control algorithm for application. Relatively compared to the basic fuzzy controller, self-organizing fuzzy controller is to optimize the control rule. However, for the further optimization and improvement of the performance of the system, there needs to combine fuzzy control with various control method. So we obtain the intelligent fuzzy controller that combined many control approaches and algorithms [10], such as PID control, adaptive control, neural network control, expert control, prediction and control genetic algorithm.

Among all of the aforementioned control approaches and algorithms of the fuzzy controller, fuzzy-PID compound control is a kind of relatively intelligent control approach that refers to the combination of fuzzy technology and the traditional PID control algorithm. This control method is a fuzzy-PI dual mode control form. The starting point of improvement is mainly due to the poorer performance of eliminating the systematic steady-state error brought by itself, and difficult to achieve high control precision. While the integral regulation of PI regulator can make the steady-state error of system keep in 0 , which has good performance of eliminating the error. Therefore, fuzzy PI controller means combined fuzzy control with PID controller that is to increase the controlling performance of steady-state [11]. At present, research and application of fuzzy PI controller is becoming increasingly available in all variety of industries and fields, involving home appliances, industrial automation, metallurgy, chemical industry, shipbuilding, aviation, space flight, and etc. Moreover, there appears fuzzy PI controller used more in the application of machine side rectifier and wind turbines. Owing to its applied object, good robustness, and better performance shown in reality resulted from the increasingly development and perfection in its related theory, the study of fuzzy PI controller applied in grid-connected inverter is a new and significantly understudied direction, which has caused many researcher's attentions and become a hot research area.

In the work, in order to solve the problem of PI parameter is often a constant and not vary when the wind speed changes, a new control scheme named fuzzy PI controller is proposed which can adjust the parameters according to the derivation of DC bus voltage and the rate of change in real-time, and therefore realizes the operation in the unit power factor by fuzzy control approach.

The rest of this paper is organized as follows: in Section II we analyze the mathematical model of the grid-connected inverter and describe the system control strategy. Section III introduce the proposed fuzzy PI controller respectively from its structure, partition fuzzy and fuzzy control rule aspect. We present our simulation and the experiment result by establishing the control system in Matlab/Simulink in Section IV. Section $\mathrm{V}$ offers our conclusion and the following job prospects. 


\section{The Analysis of Grid-connected Inverter}

In order to analyze the direct drive permanent synchronous wind power grid-connected inverter, power topology structure is simplified, it uses the three-phase voltage source instead of power grid, as shown in Figure 1.

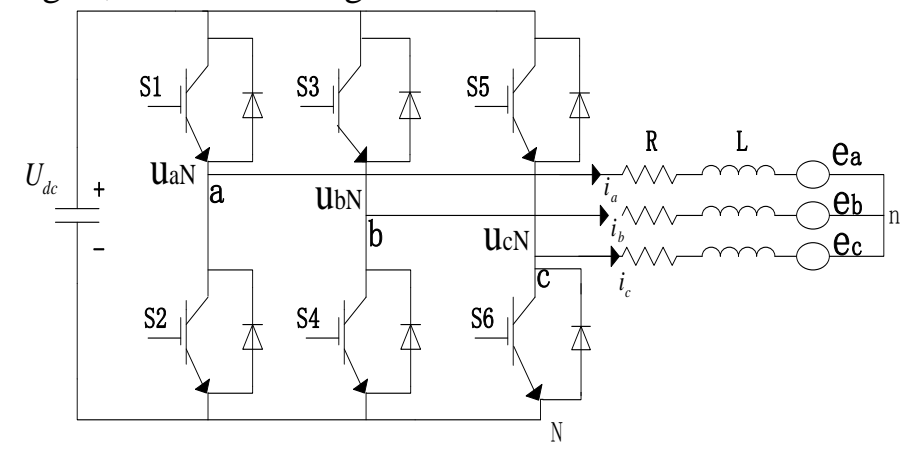

$\checkmark$ Figure 1. The Principle Diagram of Grid-Connected Inverter

According to Figure 1, the mathematical model of grid-connected inverter is

$$
\left\{\begin{array}{l}
{\left[s_{a}-\frac{1}{3}\left(s_{a}+s_{b}+s_{c}\right)\right] U_{d c}=i_{a}(j \omega L+R)+e_{a}} \\
{\left[s_{b}-\frac{1}{3}\left(s_{a}+s_{b}+s_{c}\right)\right] U_{d c}=i_{b}(j \omega L+R)+e_{b}} \\
{\left[s_{c}-\frac{1}{3}\left(s_{a}+s_{b}+s_{c}\right)\right] U_{d c}=i_{c}(j \omega L+R)+e_{c}}
\end{array}\right.
$$

Where $L$ is the filter inductance of grid side, $R$ is equivalent resistance, $i_{a}, i_{b}$ and $i_{c}$ represent the three-phase grid current, $e_{a}, e_{b}$, and $e_{c}$ are the network voltage, $U_{a N}, U_{b N}$ and $U_{c N}$ express the output voltage of inverter, $U_{d c}$ is the DC bus voltage, $s_{a}, s_{b}$ and $s_{c}$ represent the state of three-phase switching function[12].

Therefore, we can change the three-phase output voltage of the inverter by controlling the switching state of the inverter so as to change the grid current which realizing the electric energy connected power system.

In the view of three-phase full bridge inverter, it always using space voltage pulse width modulation technology(SVPWM)[13], which can improve the utilization rate of DC bus voltage because it is important for the grid-connected inverter. The major role of gridconnected inverter is to running the system under unit power factor and feedback the power into the power network. In order to achieve this propose, the double closed loop control strategy is adopted in this paper, and the system control block diagram is shown in Figure 2. 


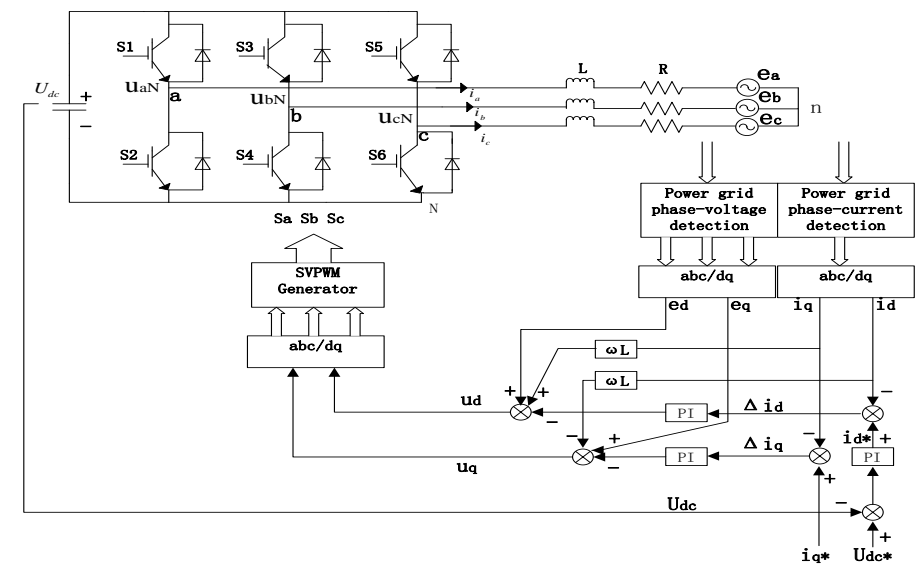

Figure 2. System Control Block Diagram $\square \square \square \square \square \square \square \square$

As shown in the Figure 2, we can see that the control system included two loops: one is the outer voltage loop that control the DC bus voltage $\left(U_{d c}\right)$ and another is the inner current which accurately control the current in $d-q$ axis $\left(i_{d}, i_{q}\right)[14]$. We can obtain the current $\left(i_{d}, i_{q}\right)$ on the $d q$ coordinate system based on coordinate transformation theory under the grid voltage vector-oriented control, which represents the three-phase line current in the active and reactive power component respectively. Therefore, controlling the parameter $i_{d}$ and $i_{q}$ can realizing the independent control of active and reactive power. That is, the outer voltage loop maintains the DC bus voltage in stable, it uses the output value which generated from the voltage loop PI controller as an given value of active current component of the grid- inverter ; The inner current loop is responsible for tracking the active current $\left(i_{d}^{*}\right)$ from output value of the outer voltage loop and the given reactive current $\left(i_{q}{ }^{*}\right)$ which can carry out the current control[15]. Consequently, according to the feedback information of voltage and current from the grid-inverter, after the double closed loop PI controller, and the formation of SVPWM wave results in the action of grid-connected inverter, it can be ensured that the output active power of generator will be feed into the power network through the grid-connected inverter, which can control the reactive power of generating system and maximize the utilization of wind power, and it can achieve the purpose to improving the efficiency and the system reliability of the grid-connected wind system.

\section{Fuzzy PI Controller}

Compared to the traditional PI control strategy, the fuzzy control method has many advantages that the controller is not required specific mathematical model while able to fulfill its function with microprocessor.

In order to maintain better stability of DC bus voltage, we can realize the accurate control by adding an voltage feedback under the condition of an given value in the adjustment of PI controller[16] . The traditional PI control method has good controlling effect for linear system because the parameters are fixed. However, when the disturbance and nonlinear conditions occurred in some external environments, the PI parameters are not change in real-time so that it will reduce the controlling effect. Therefore, the fuzzy PI control approach is adopted in this paper, according to the disturbance of external environment, it can adjust PI parameter automatically . Consequently, the outer voltage loop uses fuzzy PI controller, its output value can increase the veracity of an given value of active current from the inner current loop, so that make the output current of grid-connected inverter tracking network voltage quickly and smoothly, and improve the efficiency of the grid-connected wind system ultimately. 


\subsection{The Structure of Fuzzy Controller}

Fuzzy controller is the most important part in fuzzy control system, therefore, the property of fuzzy control system counts on the membership functions, the use of the rules of fuzzy controller, decision making and so on[17].The diagram of fuzzy controller structure is shown in Figure 3.

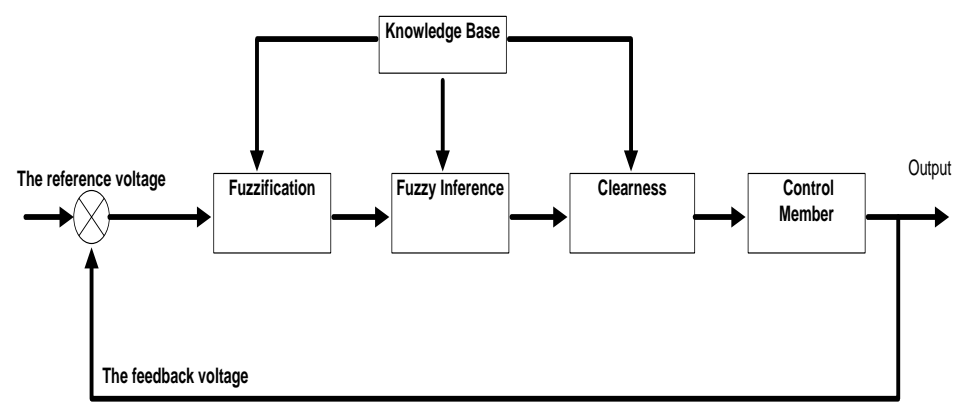

Figure 3. The Diagram of Fuzzy Controller Structure

The model of double-input and double-output is adopted in this control system, fuzzy controller serves voltage derivation and its variance ratio is input quantities, and puts PI parameters as output quantities. $E_{u}$ is the voltage derivation that represents the variance between the actual DC bus voltage and the given one, $\Delta e_{u}$ is the variance ratio of $e_{u}$. As the member of PI parameters, $k_{i}$ and $k_{p}$ are the output value of the fuzzy PI controller.

\subsection{Partition Fuzzys}

The number of fuzzy variables is relation to the control member, the higher control accuracy needs, the more variables demands [18]. While the excessive number of variables will bring about the control rules more complicated, but the less number of variables is difficult for the description of the variables, which has bad influence on the performance of fuzzy controller.

Based on knowledge and experience, the universe of discourse of $e_{u}$ is $[-1,1]$, the universe of discourse of $\Delta e_{u}$ is $[-1,1]$, the fuzzy subset of $e_{u}$ is $\{\mathrm{NB}, \mathrm{NM}, \mathrm{NS}, \mathrm{ZO}, \mathrm{PS}, \mathrm{PM}, \mathrm{PB}\}$, the fuzzy subset of $\Delta e_{u}$ is $\{\mathrm{N}, \mathrm{Z}, \mathrm{P}\}$. The membership function of $e_{u}$ and $\Delta e_{u}$ is respectively shown in Figure 4 and Figure 5.

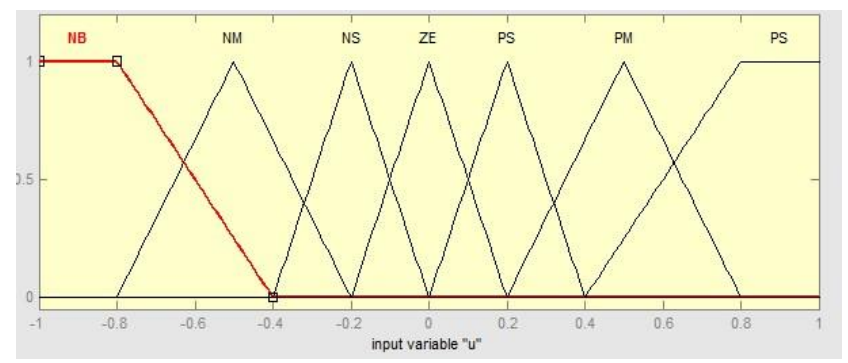

Figure 4. Membership Function of $e_{u}$ 


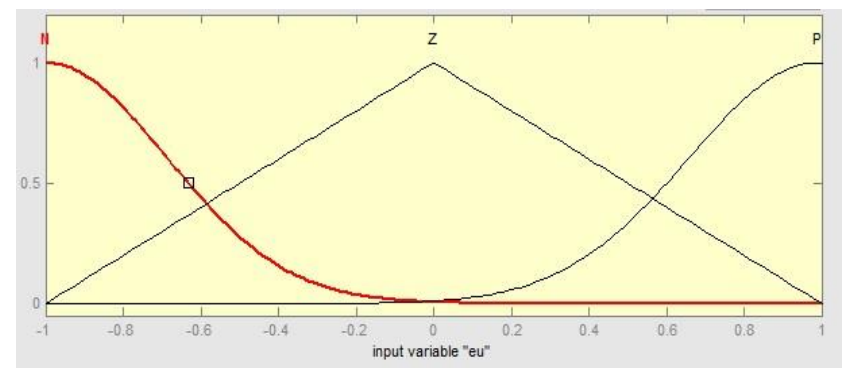

Figure 5. Membership Function of $\Delta e_{u}$

According to the experience, the universe of discourse of $k_{i}$ and $k_{p}$ are [0,1], the fuzzy subset of $k_{i}$ and $k_{p}$ are $\{\mathrm{Z}, \mathrm{S}, \mathrm{M}, \mathrm{B}\}$, the membership function of $k_{i}$ and $k_{p}$ are shown in Figure 6 and Figure 7 respectively.

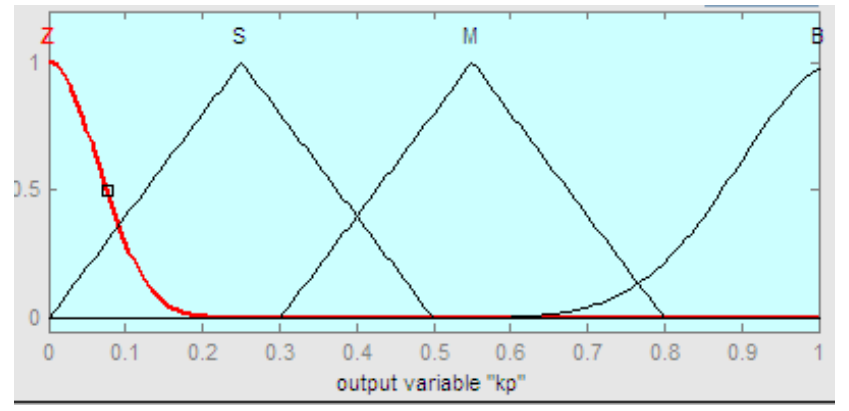

Figure 6. Membership Function of $\boldsymbol{k}_{p}$

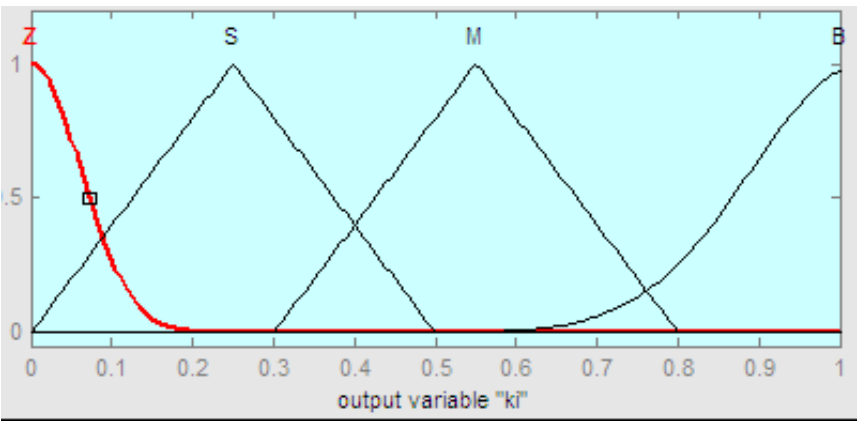

Figure 7. Membership Function of $\boldsymbol{k}_{i}$

\subsection{Fuzzy Control Rule}

The main part of fuzzy control is fuzzy control rule. It is accomplished with inferential ability of simulation through fuzzy concept, also it is a procedure of using language to induce manual control .The fuzzy control rule is to summarize the experience of the operator, and obtained the corresponding measures which are from the experience as control rules.The selected control variables has the purpose to eliminating the derivation, when it is large or even more. However, when the derivation is small, the selected control variables are using for the avoidance of overshoot, and keeping the system stable. Using the control rule.

If: $R_{i} e_{u}=A_{i}, \Delta e_{u}=B_{i}$, then $k_{i}=I_{i}, k_{p}=P_{i}$, we can obtain the fuzzy rule as follows:

$\mathrm{R}(1)$ : If $\left(e_{u}\right.$ is $\left.\mathrm{NB}\right)$ and $\left(\Delta e_{u}\right.$ is $\left.\mathrm{N}\right)$ then $\left(k_{p}\right.$ is $\left.\mathrm{B}\right)$;

$\mathrm{R}(2)$ : If $\left(e_{u}\right.$ is $\left.\mathrm{NM}\right)$ and $\left(\Delta e_{u}\right.$ is $\left.\mathrm{N}\right)$ then $\left(k_{p}\right.$ is $\left.\mathrm{M}\right)$;

$\mathrm{R}(3)$ : If $\left(e_{u}\right.$ is NS) and $\left(\Delta e_{u}\right.$ is $\left.\mathrm{N}\right)$ then $\left(k_{p}\right.$ is $\left.\mathrm{S}\right)$; 
$\mathrm{R}(4)$ : If $\left(e_{u}\right.$ is $\left.\mathrm{ZE}\right)$ and $\left(\Delta e_{u}\right.$ is $\left.\mathrm{N}\right)$ then $\left(k_{p}\right.$ is $\left.\mathrm{M}\right)$;

$\mathrm{R}(42)$ : If $\left(e_{u}\right.$ is $\left.\mathrm{PS}\right)$ and $\left(\Delta e_{u}\right.$ is $\left.\mathrm{P}\right)$ then $\left(k_{i}\right.$ is $\left.\mathrm{B}\right)$;

And the fuzzy rule base is given in Table 1 and Table 2 respectively.

Table 1. Fuzzy Control Rule of $\boldsymbol{k}_{\boldsymbol{p}} \square \square$

\begin{tabular}{|c|c|c|c|c|c|c|c|}
\hline & NB & NM & NS & ZE & PS & $\mathrm{PM}$ & PB \\
\hline $\mathrm{N}$ & B & $\mathrm{M}$ & $S$ & $\mathrm{M}$ & $S$ & M & B \\
\hline Z & B & $\mathrm{M}$ & B & Z & B & $\mathrm{M}$ & B \\
\hline$P$ & B & M & B & Z & B & $\mathrm{M}$ & B \\
\hline
\end{tabular}

Table 2. Fuzzy Control Rule of $\boldsymbol{k}_{i}$

\begin{tabular}{cccccccc}
\hline & NB & NM & NS & ZE & PS & PM & PB \\
\hline N & Z & S & M & B & S & S & Z \\
Z & Z & S & M & B & B & S & Z \\
P & Z & S & B & B & S & M & Z \\
\hline
\end{tabular}

\section{Simulation of the Fuzzy PI Controller and Experiment}

As the most important part of Matlab, Simulink provides a dynamic system modeling, simulation and comprehensive analysis of the unabridged environment[19]. The work area is established in the Simulink simulation environment, with the established simulation model of fuzzy PI controller, as shown in Figure 8.

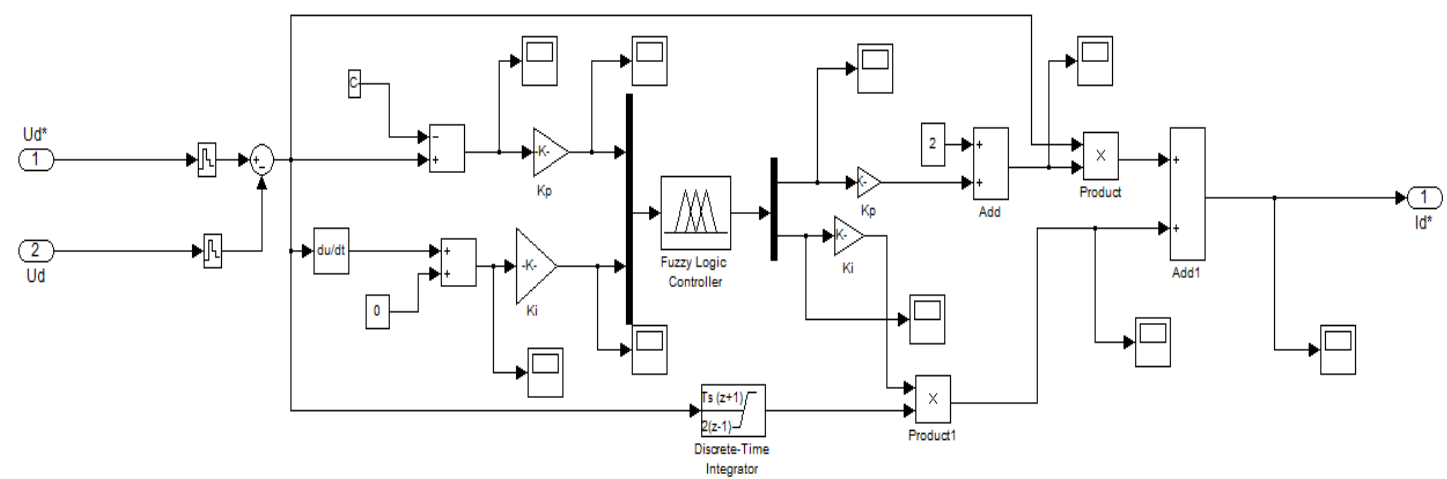

Figure 8. Simulation Module of Fuzzy PI Controller $\square \square \square \square \square \square \square \square \square$

According to the system control block, putting the files of structure established under the FIS Editor in "Fuzzy Logic Controller" in the module and then editing the parameters of each module on the basis of the corresponding data. The selected parameter list is shown as Table 3. 
Table 3. The Selected Parameter List $\square \square \square \square$

\begin{tabular}{ccc}
\hline Parameter name & Value of number & Unit \\
\hline Pole pair(p) & 4 & \\
Given speed(( $\left.{ }^{*}\right)$ & 10 & $\mathrm{~m} / \mathrm{s}$ \\
Equivalent resistance(r) & 25 & $\Omega$ \\
DC-link capacitor(C) & 0.02 & $\mathrm{~F}$ \\
The rated DC side capacitor(V) & 310 & $\mathrm{~V}$ \\
Line voltage of grid side(V) & 120 & $\mathrm{~V}$ \\
Power frequency & 50 & $\mathrm{~Hz}$ \\
Filter inductance & 1 & $\mathrm{mH}$ \\
Each phase equivalent resistance & 0.5 & $\Omega$ \\
\hline
\end{tabular}

On the basis of the selected parameter, the simulation module is built in the environment of Matlab/Simulink. In practical application, owing to the instability of wind speed, the change of wind speed can lead to the fluctuation of DC bus voltage. Experiments are conducted in the case of fluctuation of DC bus voltage as shown from Figure 9 to Figure 20.

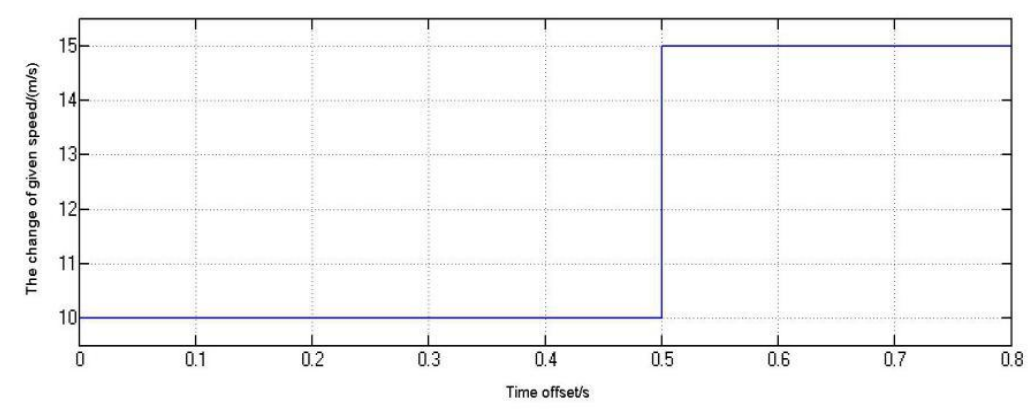

Figure 9. The Change of Given Speed $v^{\star}$ from $10 \mathrm{~m} / \mathrm{s}$ to $15 \mathrm{~m} / \mathrm{s}$

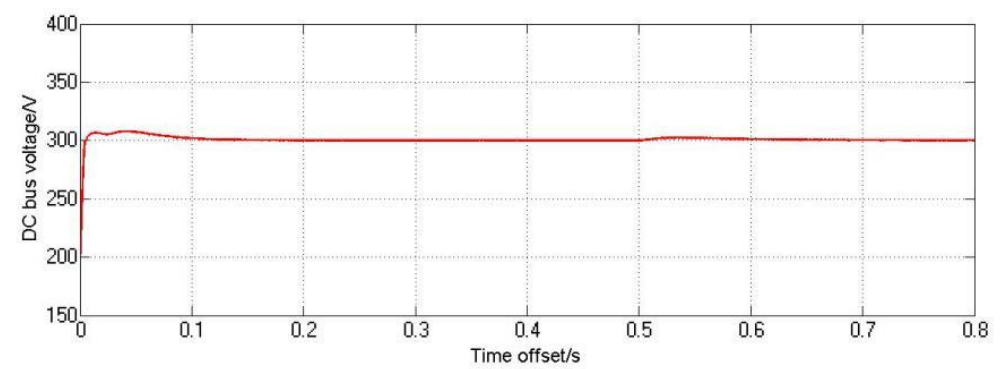

Figure 10. Waveform of DC Bus Voltage under the Traditional Control

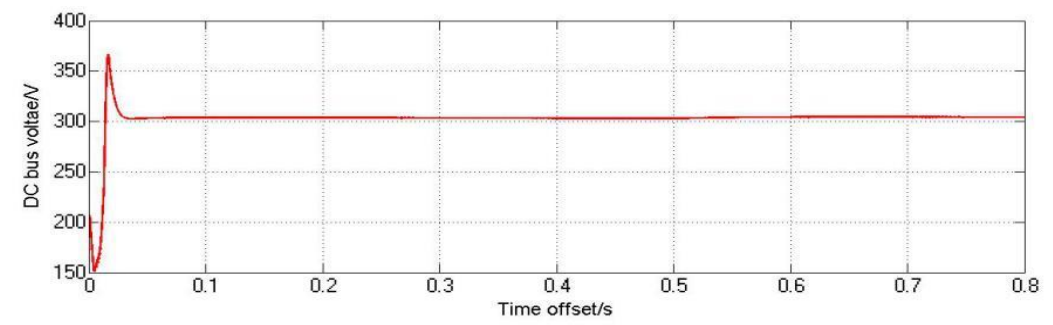

Figure 11. Waveform of DC Bus Voltage under the Fuzzy Control 


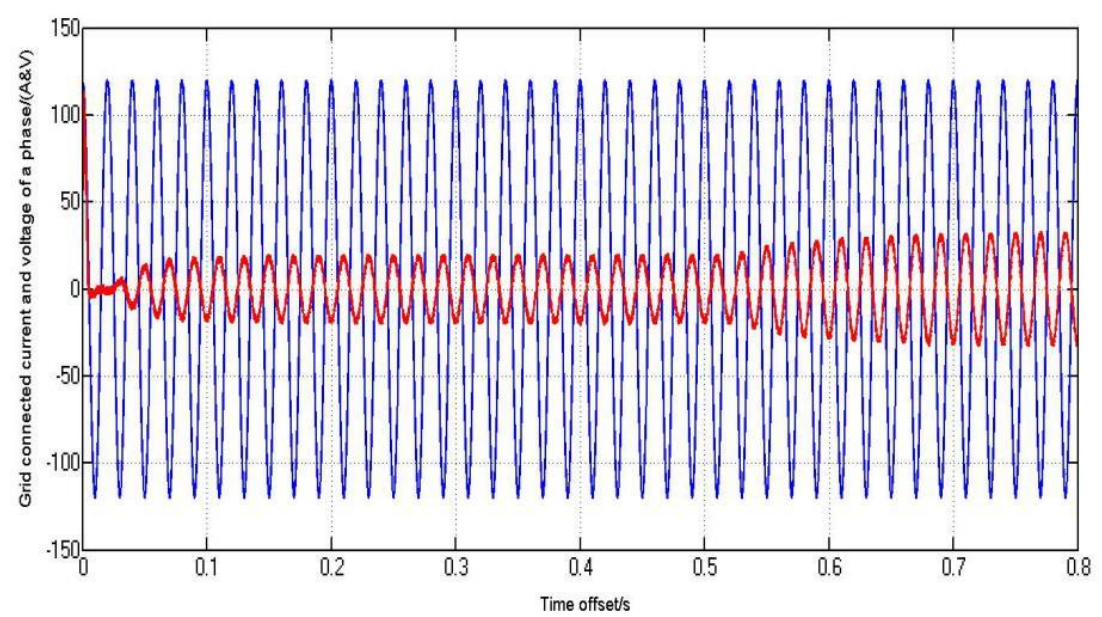

Figure 12. Grid-Connected Current and Voltage of a Phase under the Traditional Control

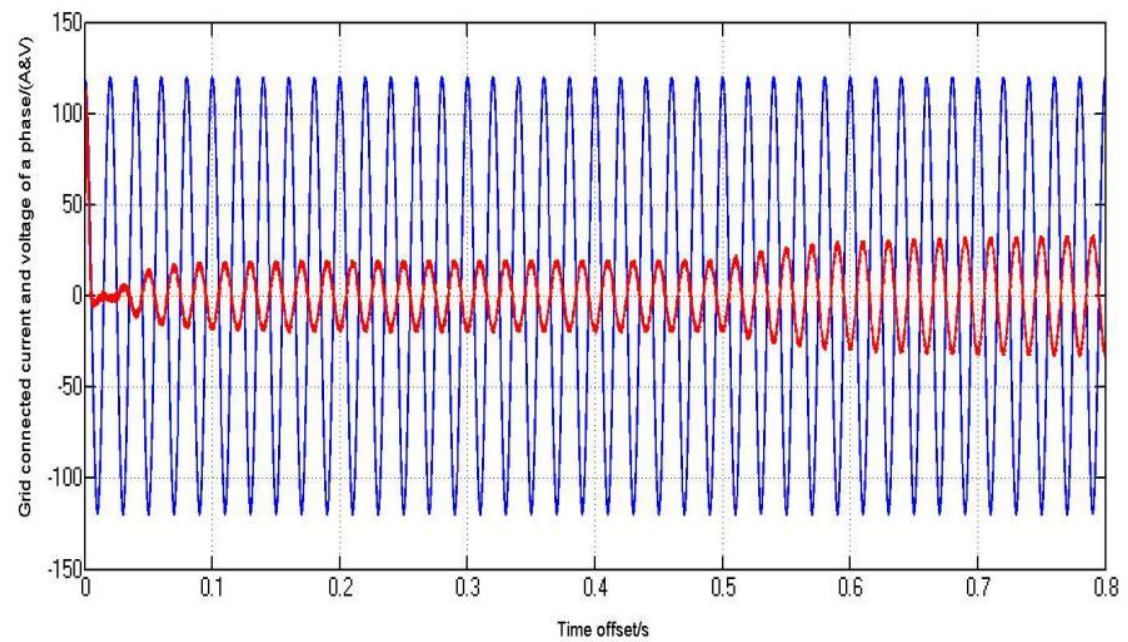

Figure 13. Grid-Connected Current and Voltage of a Phase under the Fuzzy Control

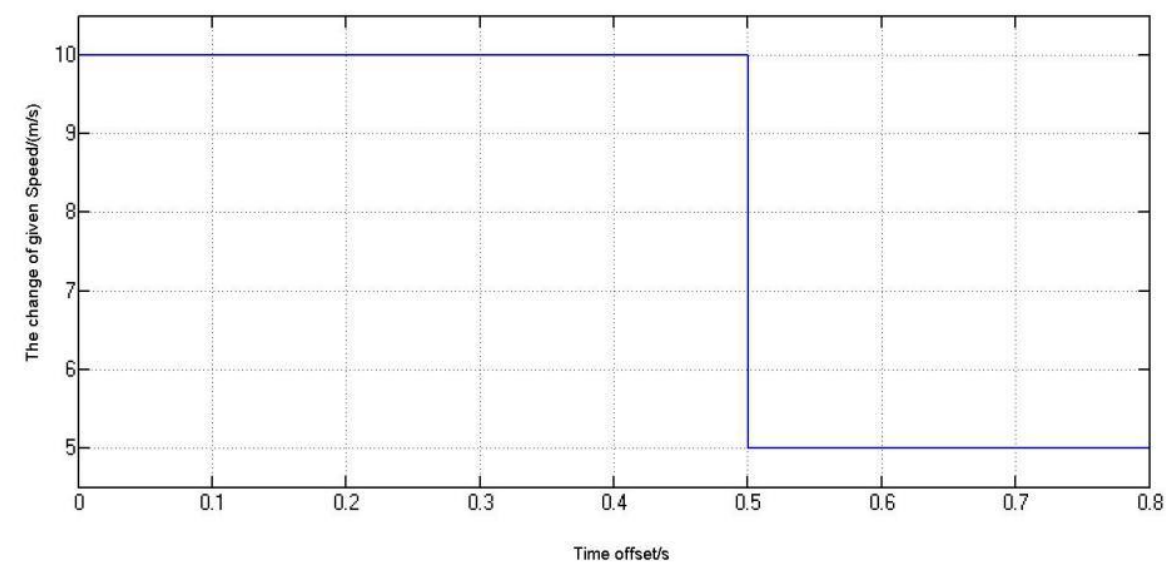

Figure 14. The Change of Given Speed $v^{*}$ from $10 \mathrm{~m} / \mathrm{s}$ to $5 \mathrm{~m} / \mathrm{s}$ 


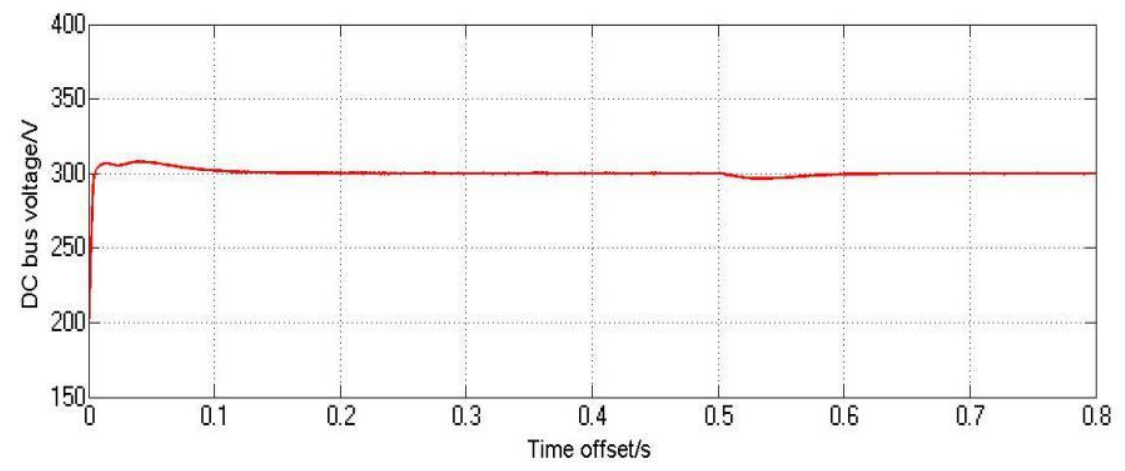

Figure 15. Waveform of DC Bus Voltage under the Traditional Control

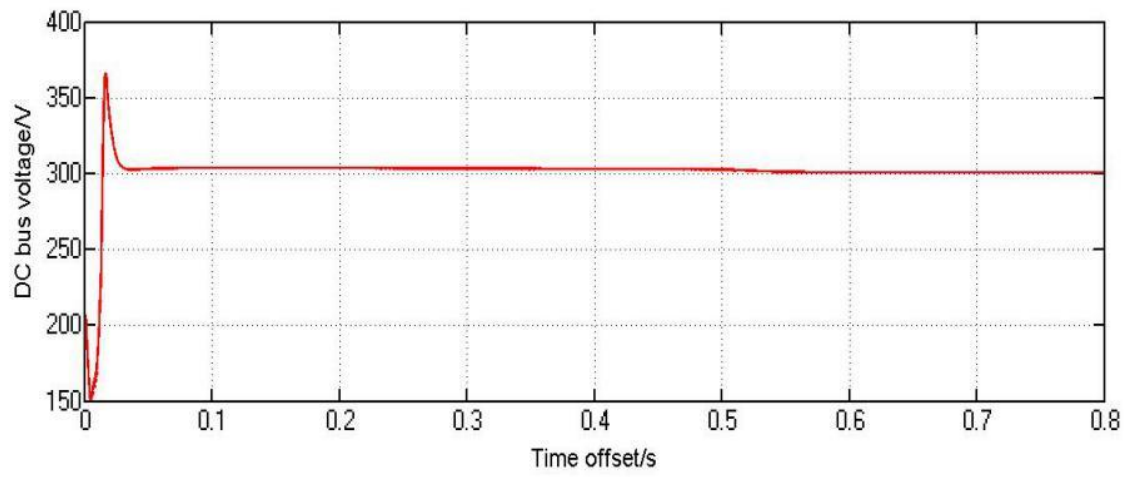

Figure 16. Waveform of DC Bus Voltage under the Fuzzy Control

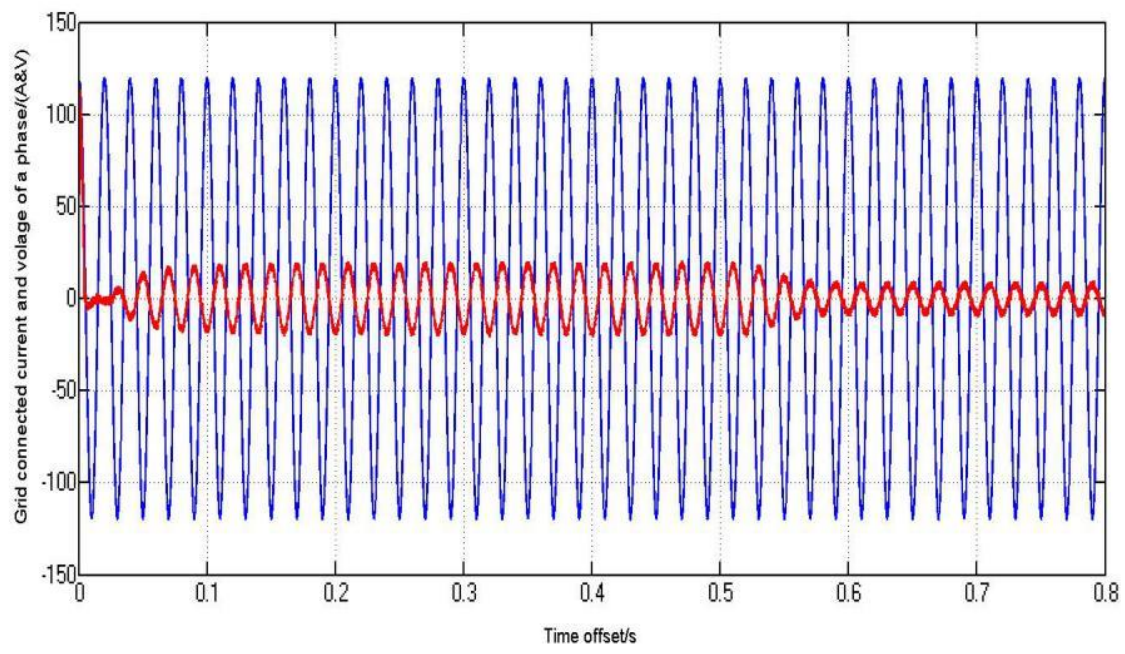

Figure 17. Grid-Connected Current and Voltage of a Phase Under the Traditional Control 


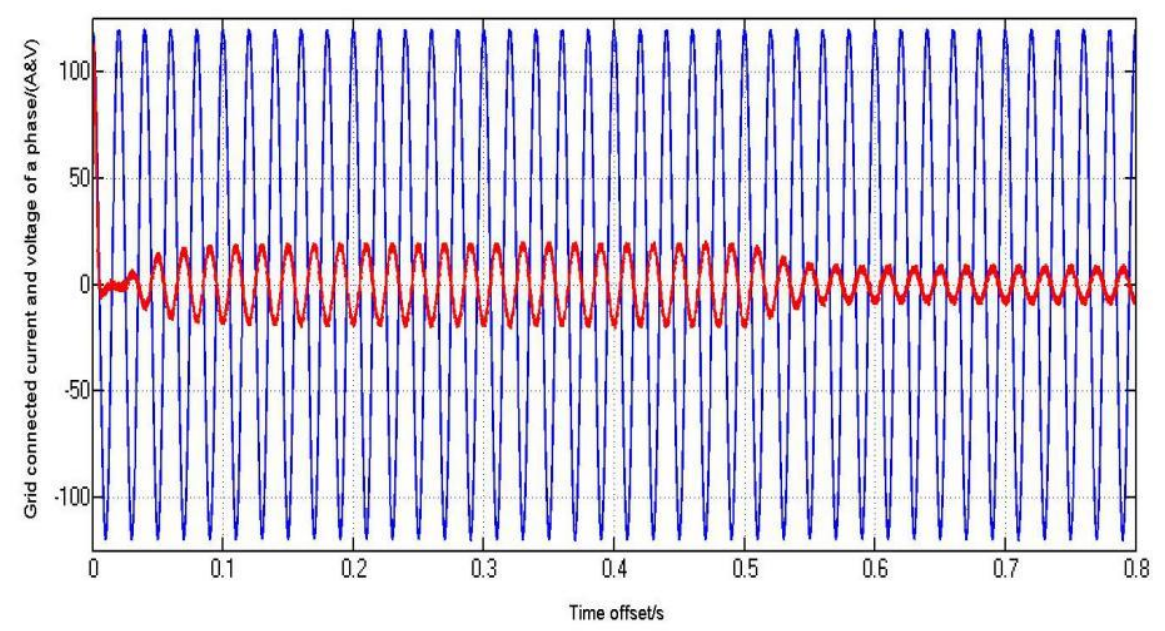

Figure 18. Grid-Connected Current and Voltage of a Phase under the Fuzzy Control

Under the assumption that the original given speed is within the rated speed range, it increases to $15 \mathrm{~m} / \mathrm{s}$, as shown in Figure 9 , or it decreases to $5 \mathrm{~m} / \mathrm{s}$ at the same time offset of $0.5 \mathrm{~s}$ as shown in Figure 14. From Figure 10 to Figure 13, comparing the waveform of DC bus voltage and grid-connected current and voltage of a phase under the traditional PI control, we can obtain that the fuzzy PI controller can adjust in real-time with the increasing of wind speed, and has the ability to react quickly and makes the DC bus voltage and grid-connected current and voltage in stable, which will be beneficial to the power quality and power conversion efficiency. Meanwhile ,the same experimental conclusion under the condition of decreasing of wind speed can be seen from Figure 15 to Figure 18.

The control approach has significant effect on the performance of the situation of active and reactive power. The related experiment is also conducted in the environment of Matlab/Simulink, as shown in Figure 19 and Figure 20.

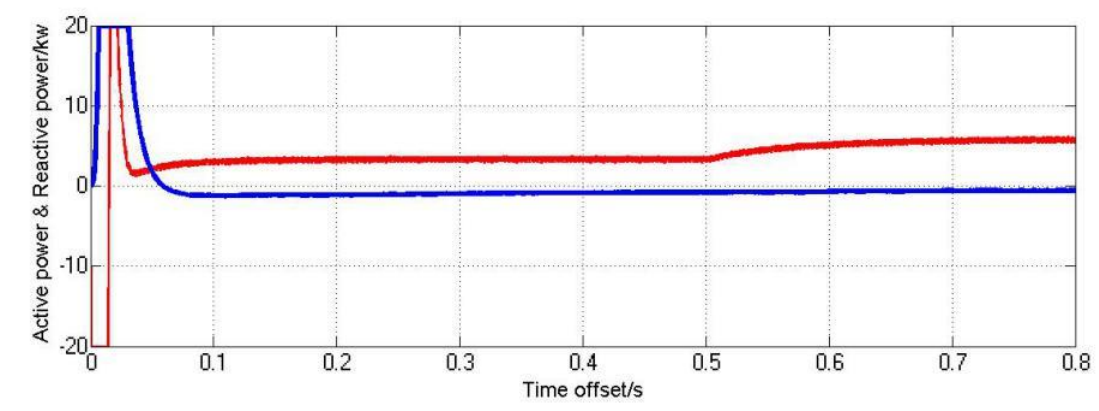




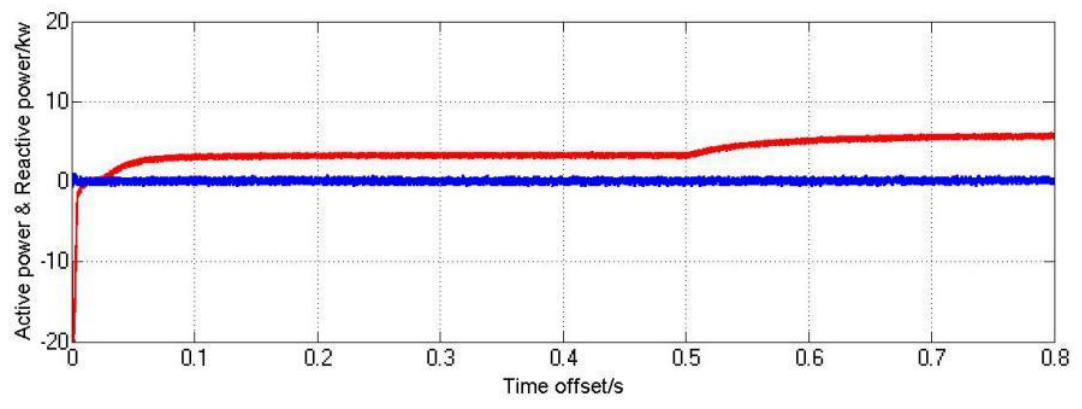

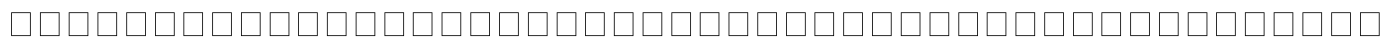

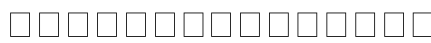

Where blue stands for the reactive power and red represents the active power. The simulation waveform can be seen that when a sudden change of wind speed, the output power of electric generator will be changed. By the switch control of grid-connected inverter, the fuzzy PI controller can be able to adjust the transmission power quickly, and guarantee the conservation of energy,so that the value of reactive power is 0 all the time, and the grid-connected inverter is running in the unit power factor.

\section{Conclusion}

After studying the characteristic of grid-connected inverter in wind power generation system. And, the traditional control strategy based on PI-type current controller and grid voltage vector-oriented control is analyzed.In view of the problem brought from PI controller, we employ fuzzy PI controller of voltage loop, $d$ and $q$ axis' current close loop control and SVPWM to realizing energy transmission and power adjustment. The experimental simulation indicate that the proposed control strategy has a good sinusoidal current, a fast dynamic response, an unity power factor and the perfect system performance, which built a good foundation for the future research of direct-drive wind power generation system.

The fuzzy PI control method provide the better performance, also the dynamic response time is a little than that of the traditional PI control method. Future work should focus on the following two fields:

(1)Current harmonics and grid-connected efficiency are also influenced by the control performance of wind power grid-connected inverter. so our future work will focus on these problems.

(2)The fuzzy PI control method proposed in this paper are the most common approaches, recently, researchers are interesting on studying the hybrid genetic algorithm and neural network technique, also is our future work.

\section{Acknowledgement}

This work was supported in part by the National Natural Science Foundation of China under contact 51177040, in part by the Science technology Support Plan Project of Hunan Province of China under contract CX2014B439, in part by the Postgraduate Technology Innovation Project of Hunan Institute of Engineering of China under contract Y14005. 


\section{References}

[1] J. Li and H. Xu, in Wind Power in Power Electronic Converter Technology, China Machine Press Publishers, Beijing, vol.1, (2008), pp.10-15.

[2] J. Li, F. Cai and L. Qiao, 2014 China Wind Power Review and Outlook, China, (2014).

[3] R. Cardenas, R. Pena, G. Asher, J. Clare and R. Blasco-Gimenez, "in Control Strategies for Power Smoothing Using a Flywheel Driven by a Sensorless Vector-Controlled Induction Machine Operating in a Wide Speed Range", IEEE Transaction on Industrial Electronics Publishers, vol. 51, (2004), pp.603-614.

[4] M. Tsili and S. Papathanassiou, in A Review of Grid Code Technical Requirements for Wind Farms, IET Renewable Power Generation Publishers, (2009), vol.3, pp.308-332.

[5] M. Altin, O. Goksu,R. Teodorescu, P. Rodriguez, B.-B.Jensen and L. Helle, "Overview of Recent Grid Codes for Wind Power Integration", Proceeding of the 12th International Conference on Optimization of Electrical and Electronic Equipment, Brasov, Romania, (2010).

[6] J. Li, S. Hu and M. Li, "Research on the Application of Parallel Back-to-Back PWM Converter on Direct-Drive Wind Power System", Proceeding of the 3rd International Conference on Electric Utility Deregulation and Restructuring and Power Technologies, Nanjing, China, (2008).

[7] V. K. Mohammad, S. Y. Ahmad and M. K. Hossein, "In Direct Power Control of DFIG Based on Discrete Space Vector Modulation”, Renewable Energy Publishers, vol.35, (2010), pp.1033-1042.

[8] M. Kiani and W. Lee, "in Effects of Voltage Unbalance and System Harmonics on the Performance of Doubly Fed Induction Wind Generators", IEEE Transaction on Industry Applications Publishers, vol.46, (2010), pp.562-568.

[9] M. E. Mokadem, V. Courtecuisse and C. Saudemont, "in Fuzzy Logic Supervisor-Based Primary Frequency Control Experiments of a Variable-Speed Wind Generator", IEEE Transactions on Power System Publishers, vol. 1, (2009), pp.407-417.

[10] B. Wu, Y. Lang and S. Kouro, "Power Conversion and Control of Wind Energy Systems", China Machine Press Publishers, China, (2012).

[11] P. Zhou, W. Zhang and Y. He, "in Improved Direct Power Control of a Grid Connected Voltage Source Converter During Network Unbalance", Journal of Zhejiang University Science C Publishers, China, vol.11, (2010), pp.817-823.

[12] X. Wang, W. Wang and H. Dai, "Wind Power in Present Situation and Prospect of Our Country", Chinese Electricity Publishers, China, (2004).

[13] P. Shi, "Prospect of Wind Power in the 21st Century", Chinese Electricity Publishers, China, (2000).

[14] B. Chen, "Electric Drive Automatic Control System", Mechanical Industry Press Publishers, China (2000), vol.3, pp.72-76.

[15] C. Zhang, H. Gu and B. Wang, "in Mathematical Model of Three-phase PWM Rectifier Based on A New Phase and Amplitude Control", Proceeding of the CSEE Publishers, (2003), vol.23, pp.28-31.

[16] R. S. Wu, S. B. Ewan and G. R. Slemon, "in Analysis of an AC-to-DC Voltage Source Converter Using PWM with Phase and Amplitude Control", IEEE Transactions on Power Electronics Publishers, (1991), vol.27, pp.355-364.

[17] T. Noguchi, H. Tomiki and S. Kondo, "in Direct Power Control of PWM Converter Without Power-source Voltage Sensors", IEEE Transactions on Industrial Application Publishers, vol. 34, (1998), pp.473-479.

[18] L. Zhu, Y. Tang and D. Zhang, "Application of Fuzzy Controller in the Speed Control Permanent Magnet Linear Motors", Proceedings of the 26th Chinese Control ConferenceHunan, China, (2007).

[19] X. Duan, H. Li and I-I. Deng, "A Simple Tuning Method for Fuzzy-PID Control”, Proceeding of the 5th International Conference on Fuzzy Systems Hong Kong, China, (2008).

[20] Y. Yong and R. Li, "in Grid-connected Inverter for Wind Power Generation System", Journal of Shanghai University Publishers, Shanghai (2009), Vol.13, pp.51-56.

\section{Authors}

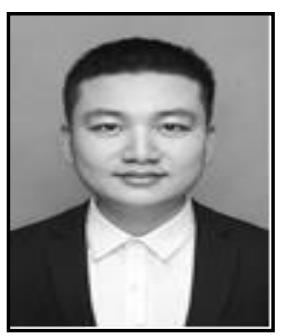

Xuan Lin, he is a Master candidate, born in Xiang Tan Hu Nan province of China in 1991. His main research area is control technology of wind power generation. 
International Journal of Control and Automation

Vol. 9, No. 12 (2016) 